\title{
Degenerated Graphite Growth in Ductile Iron
}

\section{Babette Tonn ${ }^{1, a^{*}}$, Jacques Lacaze ${ }^{2, b}$, Stephanie Duwe ${ }^{1, c}$}

${ }^{1}$ Clausthal University of Technology - Institute of Metallurgy, Robert-Koch-Str. 42, 38678 Clausthal-Zellerfeld, Germany

${ }^{2}$ CIRIMAT INPT - Centre Inter-universitaire de Recherche et d'Ingénierie des Matériaux, 4 Allée Emile Monso, BP 44362 - 31030 Toulouse cedex 4, France

aBabette.Tonn@tu-clausthal.de, bJacques.Lacaze@ensiacet.fr, 'Stephanie.Duwe@tu-clausthal.de

Keywords: ductile iron, trace elements, graphite morphology, graphite degeneracy

\begin{abstract}
As part of a study devoted to the effect of trace elements on graphite degeneracy, neareutectic ductile iron melts were prepared to which minute amounts of lead and of both lead and cerium were added. The melts were cast into an insulated Y4 mould, giving a solidification time of about 1 hour and a cooling time to room temperature of about 15 hours. In the thermal centre of the $\mathrm{Pb}$ containing sample graphite spheroids as well as intergranular lamellar graphite have been found. At the same location of the casting containing both $\mathrm{Pb}$ and $\mathrm{Ce}$, exploded as well as chunky graphite could be observed, while the formation of intergranular lamellar graphite has been suppressed.

Deep etching of the samples allowed reaching the following conclusions: i) intergranular graphite in the SG-Pb sample often, if not always, originates on graphite nodules and extends towards the last to freeze areas; ii) in one location of the SG-PbCe sample, chunky graphite strings were observed to originate on an exploded nodule, thus confirming the close relationship between these two forms of graphite. Because of the over-treatment in cerium of the SG-PbCe sample, other unusual degenerate graphite was observed which appears as coarse aggregates of "porous" graphite after deep etching.
\end{abstract}

\section{Introduction}

Several trace elements present in spheroidal graphite cast irons, either intentionally added or resulting from the charges, are known to affect graphite shape. As examples, elements like $\mathrm{Pb}, \mathrm{Sb}$ or Bi promote formation of intergranular lamellar graphite [1,2]. By addition of Ce to such melts lamellar graphite can be prevented, whereas by exceeding a critical amount of Ce exploded and chunky graphite will be formed [2].

There are different investigations about critical amounts of trace elements affecting graphite morphology in ductile cast iron as reviewed by Reynaud [3]. Buhr [2] reported that already small amounts of $0.006 \mathrm{wt} . \% \mathrm{~Pb}$ lead to lamellar graphite in the microstructure of cubes $12.7 \mathrm{~cm}$ in size, but that use of a Ce-bearing inoculant countered this detrimental effect. Pan et al. [1] showed that amounts of $0.01 \mathrm{wt} . \% \mathrm{~Pb}$ and higher lead to a graphite degeneration, namely type $\mathrm{D}$ or coral graphite for high cooling rates and spiky graphite or irregular graphite in heavier sections. However, the detrimental effect of $0.015 \mathrm{wt} . \% \mathrm{~Pb}$ in ductile iron could be almost completely neutralized by rare earth (RE) addition [1]. It was further evidenced that the necessary ratio $\mathrm{RE} / \mathrm{Pb}$ for counteracting graphite degeneration by $\mathrm{Pb}$ increases with decreasing solidification time, being 0.40.9 for heavy sections and 0.9-1.4 for fast solidification. These results are in quite good agreement with those from Javaid and Loper [4] who pointed out that the mutual neutralizing effect of $\mathrm{Pb}$ and $\mathrm{Ce}$ relates certainly to the formation of high temperature $\mathrm{Ce}-\mathrm{Pb}$ compounds. Considering the stoichiometry of the $\mathrm{Ce}_{2} \mathrm{~Pb}$ phase, a ratio of wt.\% Ce/wt.\% $\mathrm{Pb}$ of 1.3 would be necessary for neutralizing both elements. Such a simple approach does not account for the solubility of $\mathrm{RE}$ and $\mathrm{Pb}$ in cast iron melts - for which no thermodynamic database is available at present - nor for kinetic aspects of compound formation.

Furthermore, the effect of cooling rate on the critical $\mathrm{RE} / \mathrm{Pb}$ ratio points out, that there is still research needed about the mechanisms of action of low-level elements during solidification of 
ductile iron. The present study was initiated within this line of thoughts and was achieved by casting a RE-free and a RE-bearing nodular iron containing about $0.010 \mathrm{wt} \% \mathrm{~Pb}$. Various graphite degeneracies were observed in both castings which were investigated using optical and scanning electron microscopy.

\section{Research Approach}

About $35 \mathrm{~kg}$ base melt have been prepared from $70 \%$ pig iron and $30 \%$ DC04 steel in drawing grade in an induction furnace with an alumina-graphite crucible. At $1370{ }^{\circ} \mathrm{C}$, silicon has been added using a FeSi master alloy for the melt without RE (referenced SG-Pb) and a FeSiCe master alloy for the melt with RE added (referenced SG-PbCe). When the final composition has been reached $90 \mathrm{ppm}$ lead together with four parts electrolytic iron were added and the oven was quickly heated to $1445{ }^{\circ} \mathrm{C}$. The subsequent magnesium treatment was done in a preheated ladle $\left(950{ }^{\circ} \mathrm{C}\right)$. After skimming, the melt was inoculated with $0.2 \%$ ferrosilicon. The casting mould was made of furan resin bonded quartz sand, in which the mould cavity was insulated to increase the solidification time to more than one hour. A Y4 sample for each chemical composition has been cast at a temperature of $1330{ }^{\circ} \mathrm{C}$ which solidified in about $70 \mathrm{~min}$. The chemical compositions of the raw materials and treatment alloys are given in Table 1 while those of the casts are listed in Table 2. Note that 0.007 wt. $\% \mathrm{Ba}$ and $0.004 \mathrm{wt} . \% \mathrm{Sr}$ were also present in the Mg-treatment alloy.

Table 1: Chemical composition (wt.\%) of raw materials

\begin{tabular}{|l|l|l|l|l|l|l|l|l|l|l|l|l|}
\hline & $\mathrm{Al}$ & $\mathrm{C}$ & $\mathrm{Ca}$ & $\mathrm{Ce}$ & $\mathrm{La}$ & $\mathrm{Mg}$ & $\mathrm{Mn}$ & $\mathrm{P}$ & $\mathrm{S}$ & $\mathrm{Si}$ & $\mathrm{Ti}$ & $\mathrm{Zr}$ \\
\hline sorel iron & 0.005 & 3.87 & - & 0 & 0 & 0 & 0.006 & 0.012 & 0.01 & 0.797 & 0.008 & 0.002 \\
\hline DC04 & 0.04 & 0.004 & 0 & 0 & 0 & - & 0.1 & 0.009 & 0.006 & 0.015 & 0.08 & 0.002 \\
\hline $\begin{array}{l}\text { Mg-treatment } \\
\text { alloy }\end{array}$ & 0.757 & - & 1.74 & 0.066 & 0.045 & 6.03 & 0.297 & 0.010 & 0.005 & 44.8 & 0.045 & 0.008 \\
\hline FeSi & - & 0.09 & 0.15 & 0 & - & - & - & - & - & 75.1 & - & - \\
\hline
\end{tabular}

Table 2: Chemical composition (wt.\%) of experimental cast irons

\begin{tabular}{|l|l|l|l|l|l|l|l|l|l|}
\hline Melt & $* \mathrm{CE}$ & $\mathrm{C}$ & $\mathrm{Si}$ & $\mathrm{Mn}$ & $\mathrm{P}$ & $\mathrm{S}$ & $\mathrm{Mg}$ & $\mathrm{Pb}$ & $\mathrm{Ce}$ \\
\hline $\mathrm{SG}-\mathrm{Pb}$ & 4.22 & 3.37 & 2.76 & 0.06 & 0.029 & 0.012 & 0.061 & 0.012 & 0.006 \\
\hline SG-PbCe & 4.32 & 3.51 & 2.63 & 0.08 & 0.039 & 0.012 & 0.057 & 0.009 & 0.020 \\
\hline
\end{tabular}

${ }^{*} \mathrm{CE}=$ Carbon Equivalent $=$ wt.\% C + 0.31 wt.\% Si + 0.33 wt.\% P - 0.027 wt.\% Mn + 0.4 wt.\% S

Considering, that $\mathrm{Ce}$ and $\mathrm{Pb}$ exclusively form the phase $\mathrm{Ce}_{2} \mathrm{~Pb}$, the optimum ratio of the amounts of elements in the melt should be $\mathrm{Ce} / \mathrm{Pb}=1.3$. The melt $\mathrm{SG}-\mathrm{Pb}$ contains a significant excess of $\mathrm{Pb}$ with a ratio of $\mathrm{Ce} / \mathrm{Pb}=0.4$. On the contrary, the ratio is 2.2 for alloy SG-PbCe which means a significant excess of Ce. To account for the size of the $\mathrm{Y} 4$ blocks, $\mathrm{Mg}$ was added to achieve quite an elevated level which also means that micro-porosity formation is expected in the castings.

After cooling down the feeder was cut off. Samples were prepared from the geometric centre of the remaining volume for a microstructure analysis. The sampling point is shown in Fig. 1.

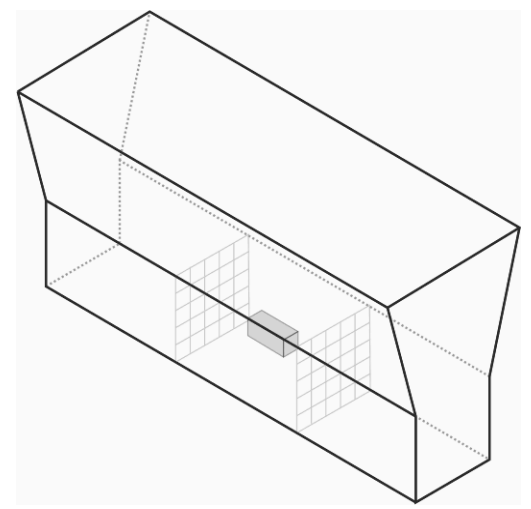

Figure 1: Y4 sample with sampling point for microstructure analysis 
To investigate the graphite morphology the metallographic samples were grinded and polished, etched by $\mathrm{NaOH}+\mathrm{CrO}_{3}$ as well as deep etched to uncover the graphite. The samples were then examined using light microscopy as well as scanning electron microscopy.

\section{Results}

Fig. 2 shows an overview of the microstructure of the two samples where different types of degenerated graphite precipitates are visible. In Fig. 2-a (SG-Pb alloy) intergranular flake graphite and some Widmanstätten graphite can be observed, as well as lamellar outgrowths from the graphite spheroids. These features seem characteristic of $\mathrm{Pb}$ addition [3]. The nodularity was evaluated to $73.5 \%$. The microstructure in Fig. 2-b (SG-PbCe alloy) shows no intergranular flake graphite but exploded graphite as well as chunky graphite. Here, the nodularity is $82 \%$. The graphite precipitate count amounts to $100 \mathrm{~mm}^{-2}$ for the $\mathrm{SG}-\mathrm{Pb}$ sample and $113 \mathrm{~mm}^{-2}$ for the SG$\mathrm{PbCe}$ one.
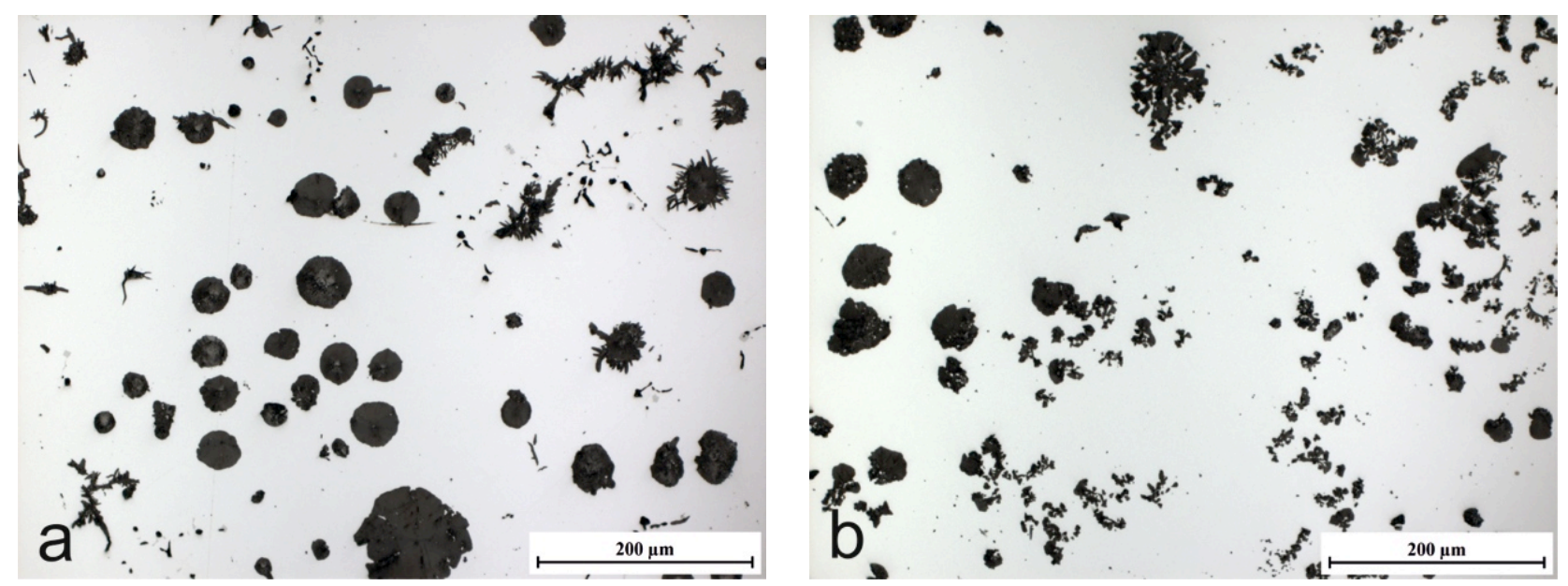

Figure 2: Microstructure of SG-Pb (a) and SG-PbCe (b) samples

It can thus be confirmed that $\mathrm{Ce}$ compensates the detrimental effect of $\mathrm{Pb}$ on graphite morphology as the sample containing both $\mathrm{Ce}$ and $\mathrm{Pb}$ does not show lamellar graphite anymore. However, the excess of $\mathrm{Ce}$ in the melt promoted the formation of degenerated spheroids and chunky graphite.

Fig. 3 shows the microstructures after etching the samples with $\mathrm{NaOH}+\mathrm{CrO}_{3}$. In both samples a two-fold distribution in size of graphite precipitates may be observed. Large precipitates are expected to result from graphite having grown freely for a while in the melt and small ones should have appeared during bulk eutectic reaction. Furthermore, it becomes visible that chunky graphite as well as exploded graphite in the SG-PbCe alloy are located in areas first solidified (Figs. 3-b and $3-\mathrm{d}$ ), whereas the intergranular flake graphite in the SG-Pb alloy can be found in the last to freeze regions (Figs. 3-a and 3-c). Also, in sample SG-Pb, lamellar outgrowths from graphite spheroids are seen to develop towards the last to freeze regions (Fig. 3-c).

Both samples show microporosity at grain boundaries which could be either shrinkage porosity favoured by the high magnesium content or water soluble phases which disappeared during grinding and polishing of the samples. 

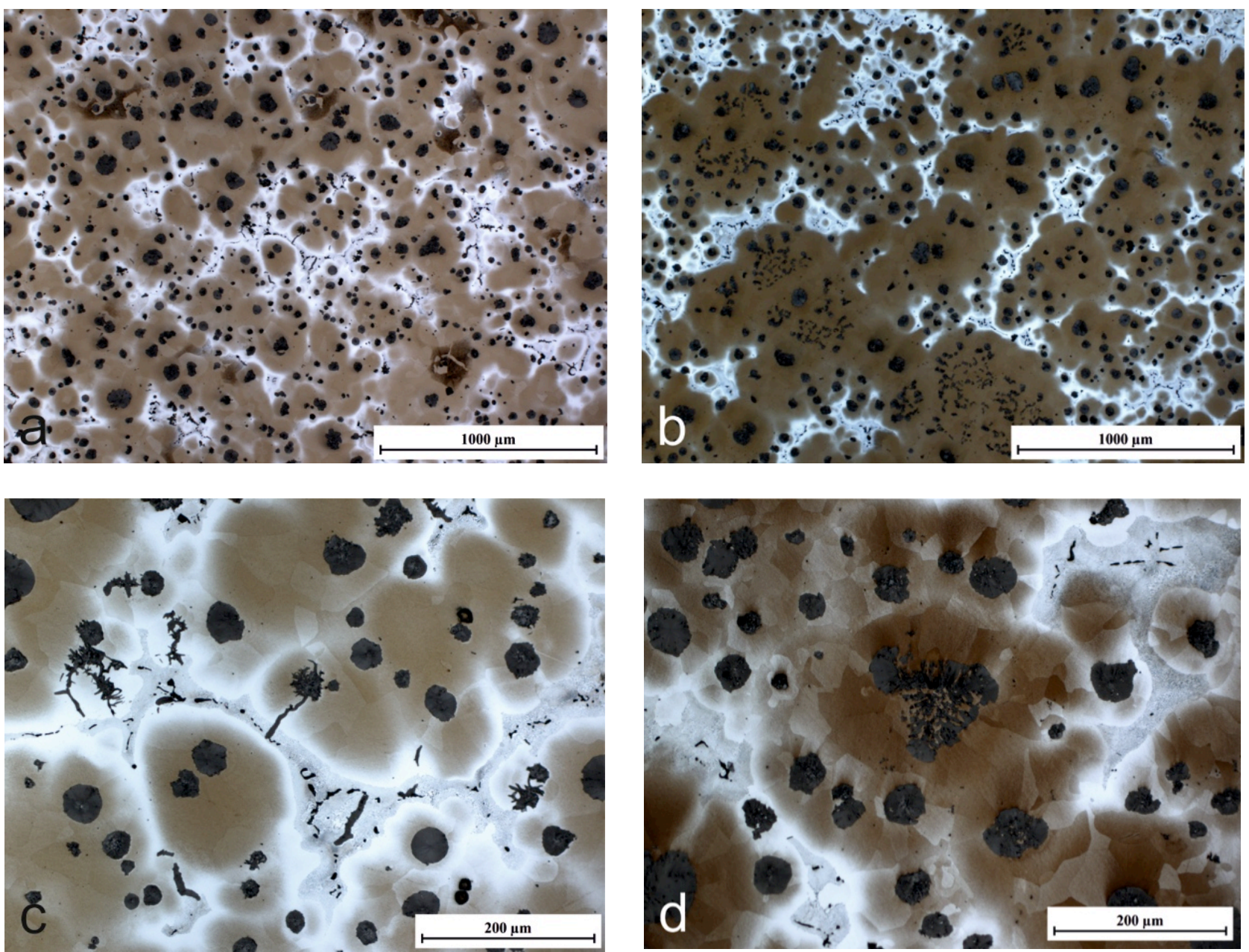

Figure 3: $\mathrm{NaOH}+\mathrm{CrO}_{3}$ etched micrographs of the samples $\mathrm{SG}-\mathrm{Pb}(\mathrm{a}$ and $\mathrm{c}$ ) and $\mathrm{SG}-\mathrm{PbCe}(\mathrm{b}$ and d).

The last to freeze regions appear bright coloured

In Fig. 4 the graphite morphology is illustrated again for both samples but this time as seen under polarized light. The micrographs of the sample SG-Pb (Figs. 4-a and 4-c) show graphite spheroids with well-developed sectors having grown with the $c$ crystallographic direction of graphite being radially oriented. From this, it is clearly evidenced that the lamellar outgrowths from the surface of the spheroids developed along the $\boldsymbol{a}$ crystallographic direction of graphite.

In Fig. 4-b from sample SG-PbCe, it appears that several chunky graphite strings developed from the outer surface of an exploded spheroid located on the top left of the image. This confirms the close relationship between these two degenerate forms of graphite. As it is well established that chunky graphite results from coupled eutectic growth of austenite and graphite (see for example the review by Lacaze et al. [5]), this micrograph indicates that the development of the exploded nodule was replaced by coupled growth with chunky graphite when austenite appeared.

The strings of chunky graphite are made of small blocks piled-up one upon each other which are very much alike conical sectors in spheroidal graphite. These blocks appear with bright and dark contrasts along most of the strings: it is unsure if this is a feature necessary for the growth of the strings or if rotation of the small blocks making up the strings occurred during growth. Finally, Fig. 4-d presents another area from the same SG-PbCe sample where graphite precipitates are looking in between exploded graphite and chunky graphite. It is suggested, that this area relates to a section of the outer boundary of a chunky cell where the graphite becomes coarser. 

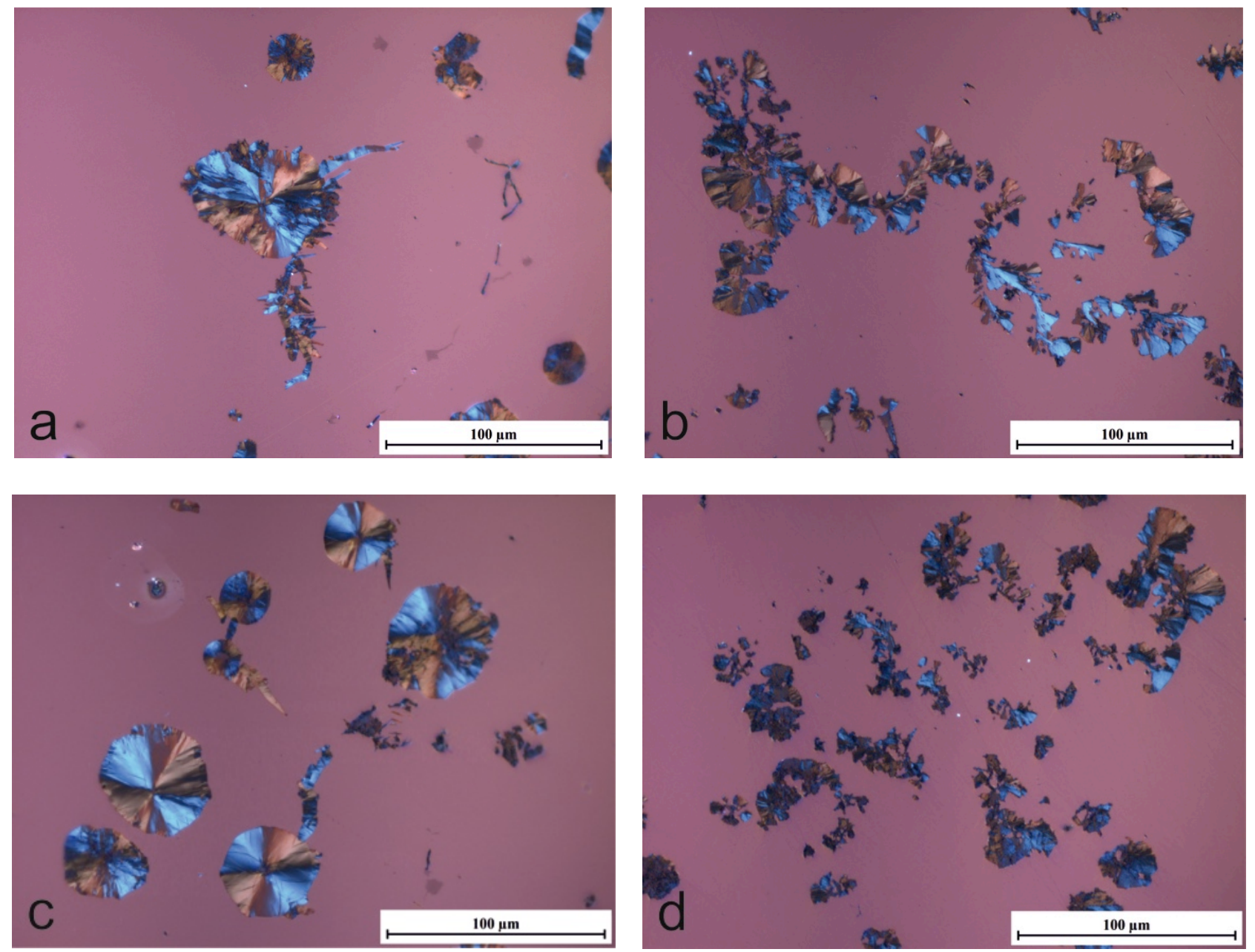

Figure 4: Graphite morphology under polarized light of sample SG-Pb (a and c) and sample SG$\mathrm{PbCe}(\mathrm{b}$ and $\mathrm{d})$

In Fig. 5 deep etched micrographs of the sample SG-Pb are presented. Fig. 5-a shows a lamellar outgrowth from a spheroid while Fig. 5-b shows that such outgrowth may develop as what is known as "intergranular flake graphite". Fig. 6-a shows another example of such flake having developed from a spheroid and Fig. 6-b presents an enlargement of the flake that illustrates the fact that Widmanstätten graphite plates present definite orientations with respect to the lamellae onto which they developed. Comparing Fig. 5-a and 6-b, it hardly appears possible to decide when the outgrowths seen in Fig. 5-a developed, i.e. during solidification or by solid-state precipitation as Widmanstätten graphite. 

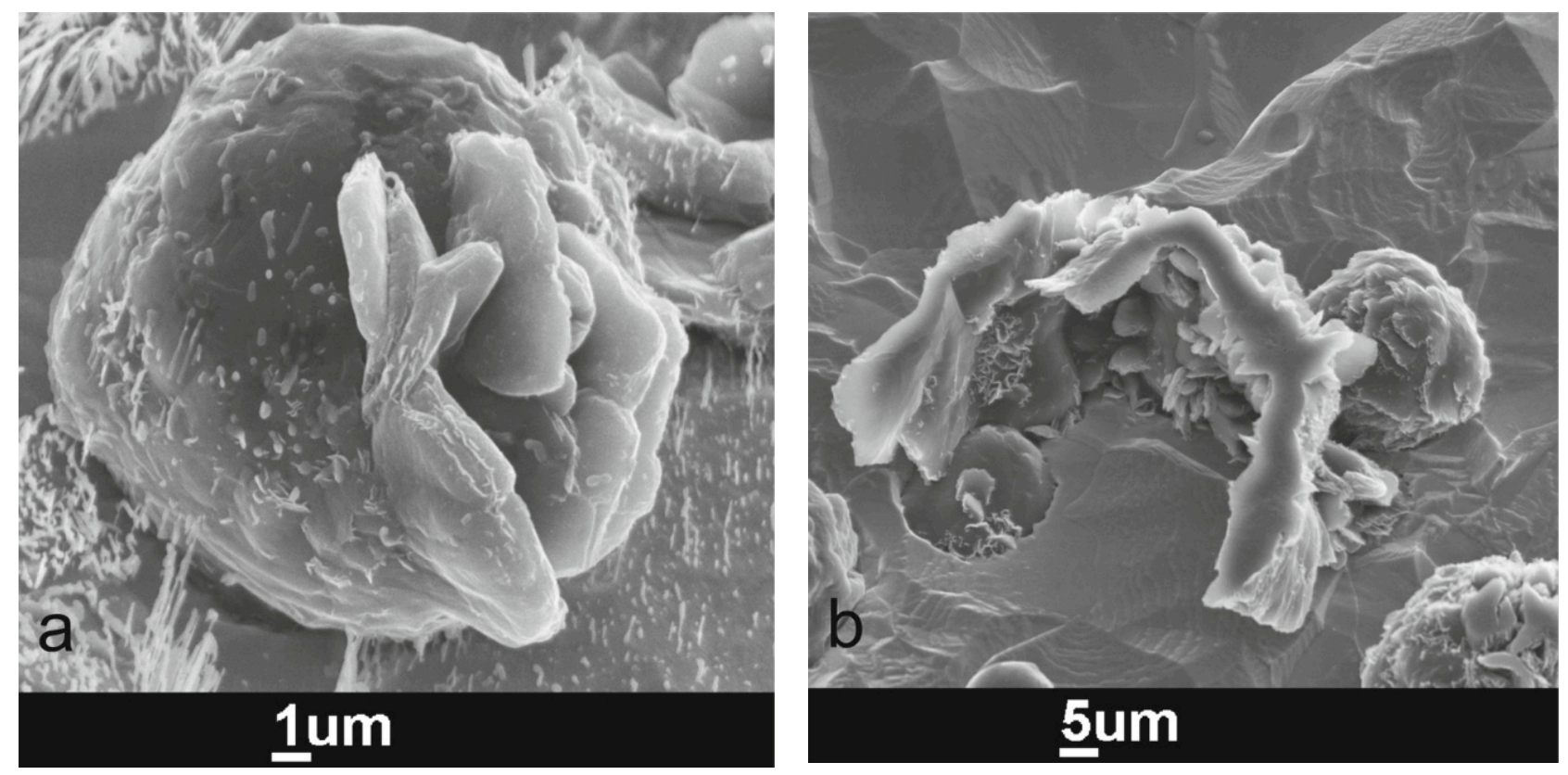

Figure 5: SEM micrographs of the sample SG-Pb after deep-etching
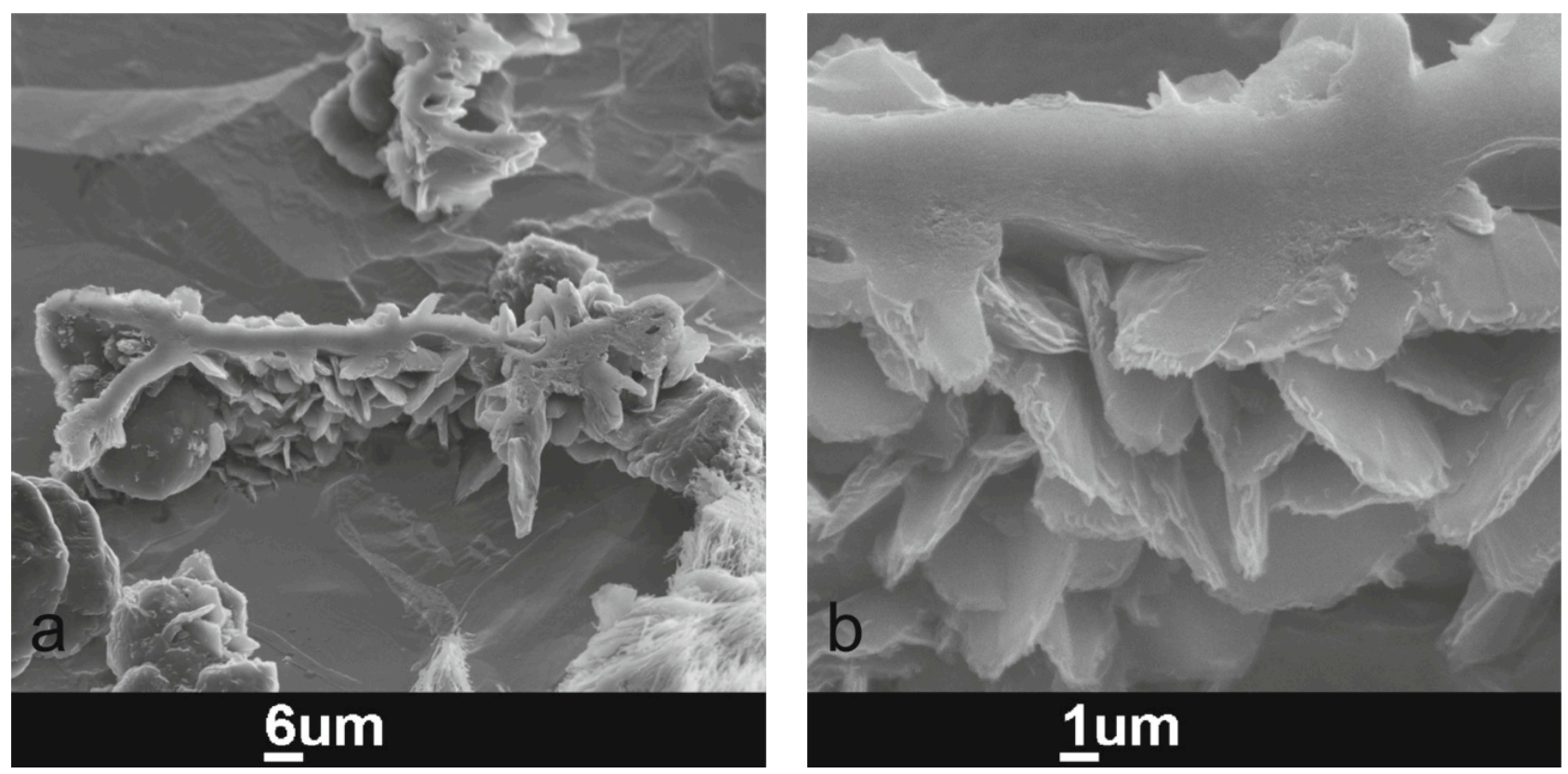

Figure 6: SEM micrographs of a graphite flake in deep-etched SG-Pb sample (a) and enlargement of the central part of the flake (b)

Deep-etching was also applied to the SG-PbCE sample as illustrated in Fig. 7 which shows views at various enlargements of chunky graphite strings. During growth of the eutectic cell, the strings of chunky graphite are seen to branch as would be the case of a cell with lamellar, undercooled or coral graphite. As could be seen in Fig. 4-b, it is evident in Fig. 7-d that the overall direction of graphite growth in the chunky cell is along the $c$ crystallographic direction of graphite.

Following Hunter and Chadwick [6] who used thermal etching, it should be noted that the relief marks seen on the side of the cones are certainly produced by deep-etching. The striations reveal the basal orientation of graphite but their scale cannot be related to the scale on which graphite growth occurs without further investigation. To the best of the knowledge of the authors, no such relation has ever been reported up to now which would need to complement SEM observations with local crystallographic information as diffraction pattern using transmission electron microscopy or Kikuchi patterns recorded on a SEM or a scanning transmission electron microscope (STEM). 

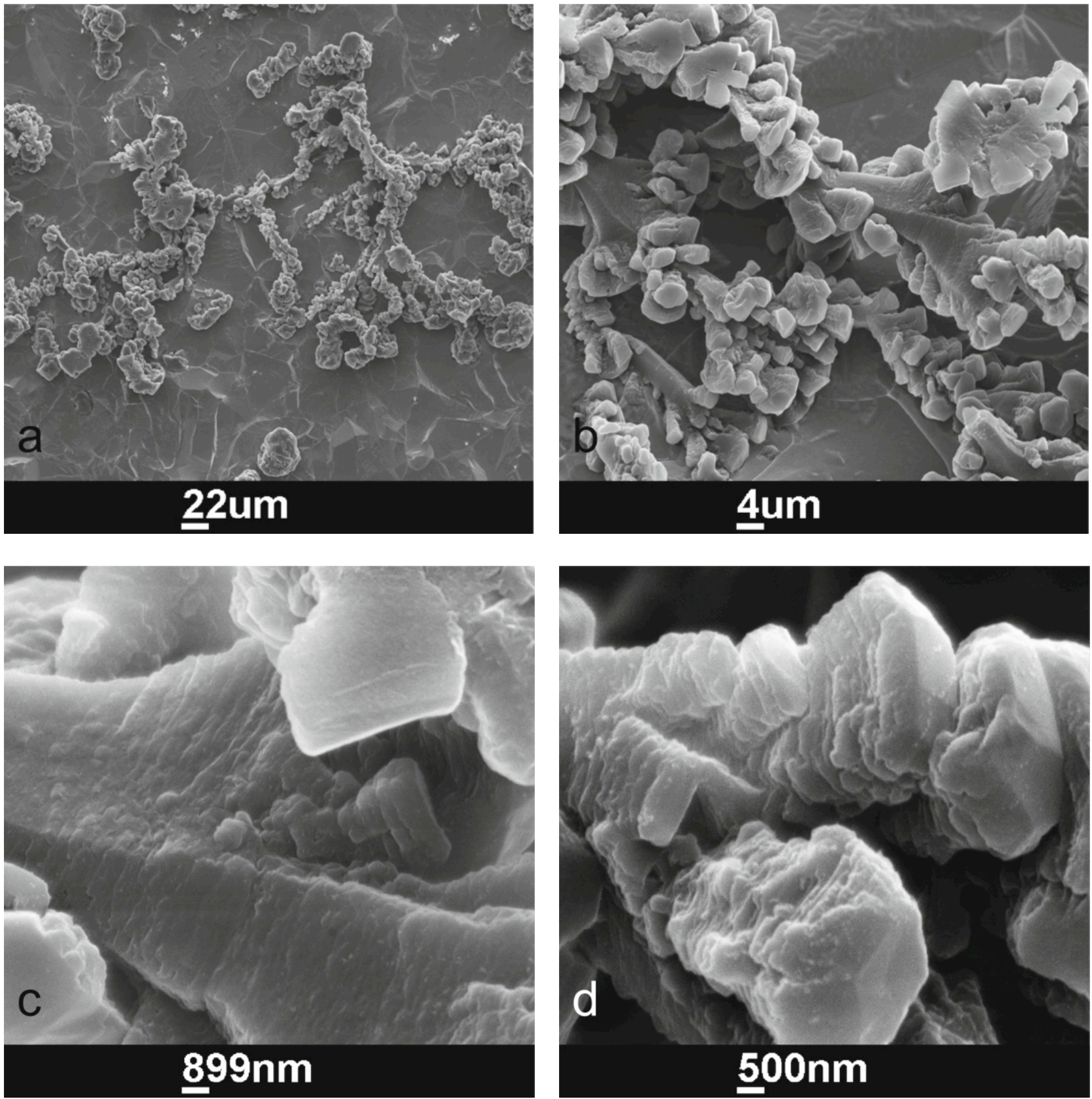

Figure 7: Chunky graphite in deep etched SG-PbCe sample

In the middle-top of Fig. 2-b a graphite precipitate is observed that could be seen at first as part of a dendrite. Several of such precipitates were observed on the metallographic section of sample SG-PbCe. However, after deep etching it appeared that these precipitates are quite coarse and large aggregates of "porous" graphite as illustrated in the SEM micrograph in Fig. 8-a. The overall outer shape of such precipitates is striking and does not give any clue on the mechanism by which they developed. Finally, the graphite precipitates seen in Fig. 8-b suggest that there can be a real continuity between spheroids, exploded graphite, chunky graphite and other aggregates as in Fig. 8-a. 

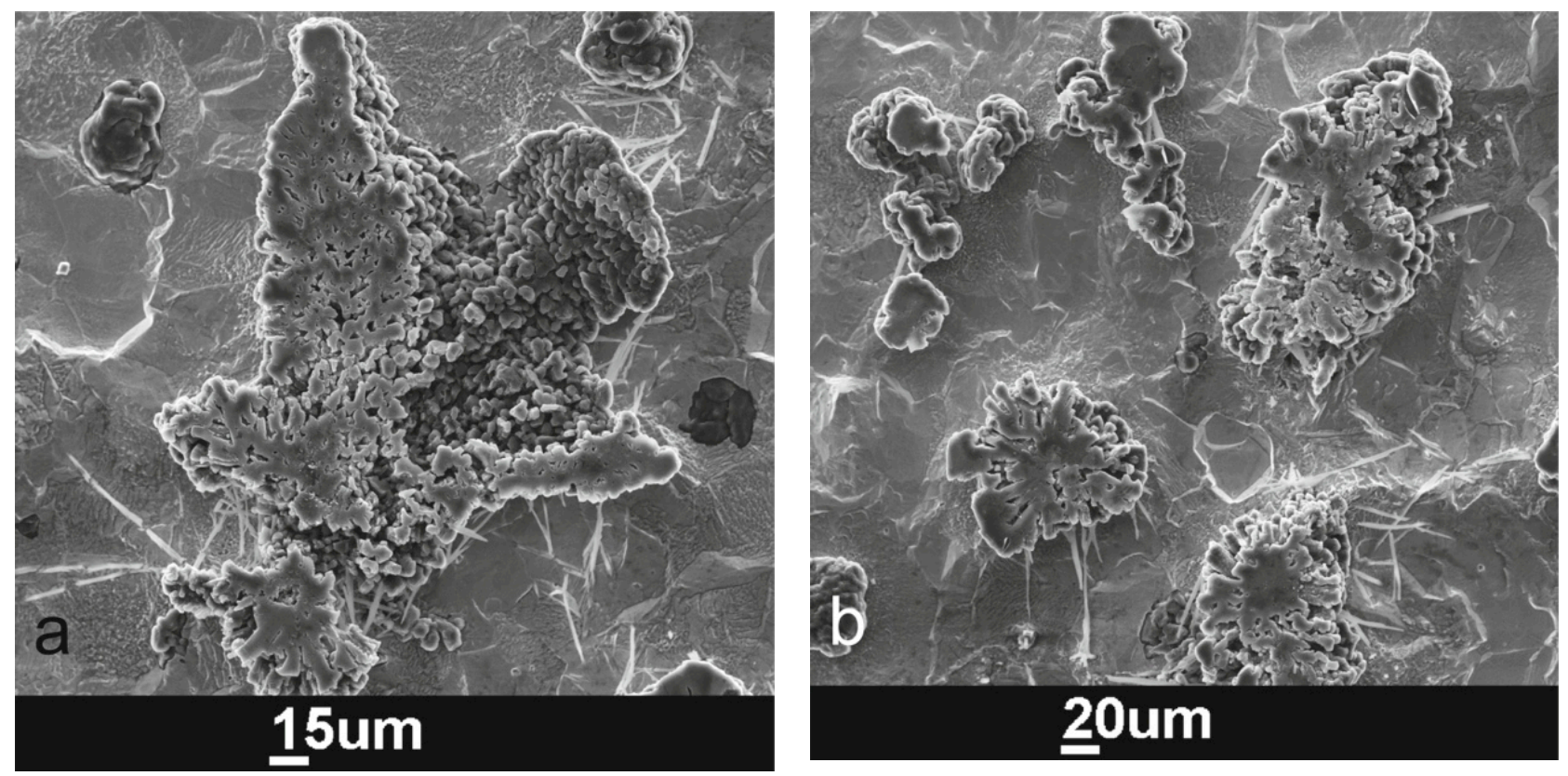

Figure 8: Graphite precipitates appearing as "porous" graphite in 2D section but seen to be quite coarse precipitates after deep etching (a) and cluster of graphite precipitates ranging between irregular nodule to chunky graphite string (b)

\section{Summary}

In the micrographs two different types of degenerated graphite were found. The addition of $\mathrm{Pb}$ to the melt led to lamellar graphite growth which started from spherolites. With a combined addition of $\mathrm{Ce}$ and $\mathrm{Pb}$ no lamellae were found anymore. However, the exceeding amount of Ce leaded to exploded as well as to chunky graphite.

Since there is either lamellar or chunky growth, it can be assumed, that $\mathrm{Ce}$ and $\mathrm{Pb}$ interact with each other. However, no phases containing both elements could be found. A reason could be the high water solubility of these phases which disappear during metallographic preparation of the samples.

\section{References}

[1] E.N. Pan, C.N. Lin, H.S. Chiou, Effects of lead and solidification conditions on graphite structure of heavy-section DI, AFS Trans. 103 (1995) 265-273.

[2] R.K. Buhr, The effects of $\mathrm{Pb}, \mathrm{Sb}, \mathrm{Bi}$ and $\mathrm{Ce}$ on microstructure of heavy section nodular iron castings, AFS Trans. 79 (1971) 247-252.

[3] A. Reynaud, Oligo-éléments et fontes, Editions Techniques des Industries de Fonderie, Sèvres, 2005.

[4] A. Javaid, C.R. Loper, Production of Heavy-Section Ductile Cast Iron, AFS Trans. 103 (1995) $135-150$.

[5] J. Lacaze, L. Magnusson-Åberg, J. Sertucha, Review of microstructural features of chunky graphite in ductile cast irons, Proceedings of the "Keith Millis symposium", Nashville, 2013, AFS, pp. 232-240.

[6] M.J. Hunter, G.A Chadwick, Structure of spheroidal graphite, JISI 210 (1972) 117-123. 